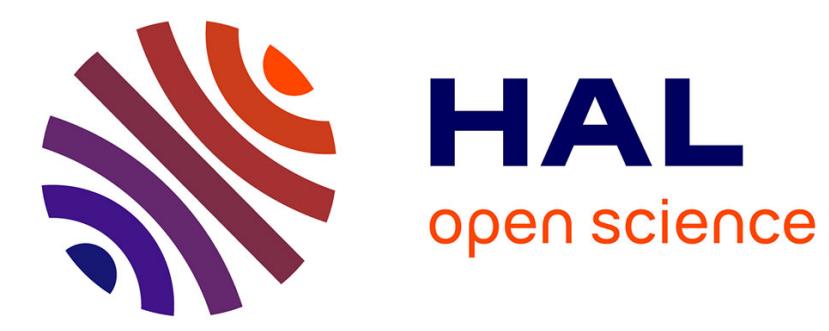

\title{
2D-Electrical Resistivity Imaging for Sike Survey: Impact of the a Priori Information Management
}

Yannick Fargier, Sergio Palma-Lopes, Cyrille Fauchard, Daniel Francois, Philippe Cote

\section{To cite this version:}

Yannick Fargier, Sergio Palma-Lopes, Cyrille Fauchard, Daniel Francois, Philippe Cote. 2D-Electrical Resistivity Imaging for Sike Survey: Impact of the a Priori Information Management. Near Surface Geoscience 2012 - 18th European Meeting of Environmental and Engineering Geophysics, Sep 2012, PARIS, France. pp. 582-586, 10.3997/2214-4609.20143357 . hal-01951058

\section{HAL Id: hal-01951058 https://hal.science/hal-01951058}

Submitted on 11 Dec 2018

HAL is a multi-disciplinary open access archive for the deposit and dissemination of scientific research documents, whether they are published or not. The documents may come from teaching and research institutions in France or abroad, or from public or private research centers.
L'archive ouverte pluridisciplinaire $\mathbf{H A L}$, est destinée au dépôt et à la diffusion de documents scientifiques de niveau recherche, publiés ou non, émanant des établissements d'enseignement et de recherche français ou étrangers, des laboratoires publics ou privés. 
B29

\title{
2D-Electrical Resistivity Imaging for Sike Survey: Impact of the a Priori Information Management
}

\author{
Y. Fargier* (EDF-R\&D), S. Palma Lopes (LUNAM University, IFSTTAR, \\ MACS7), C. Fauchard (CETE Normandie Centre), D. François (EDF-R\&D, \\ P1E) \& P. Côte (LUNAM Université, IFSTTAR, MACSO)
}

\section{SUMMARY}

In France, EDF (Électricité De France) is in charge of managing the large hydraulic structure stock dedicated to producing hydroelectricity. This responsability is associated with high economical and safety issues. Electrical Resistivity Imaging (ERI) is being widely used on earth embankment dikes, either for extensive survey of large sections (a few $\mathrm{km}$ ) or for higher resolution surveys on shorter sections (a few $100 \mathrm{~m})$.

However, the processing of extensive longitudinal survey with conventional $2.5 \mathrm{D}$ software is likely to yield image artefacts. This study aims to show that a bad management of the dike complexity in the inversion process is the origin of these artifacts.

To overcome this limitation, a new inversion algorithm specially created to take into account the complex behaviour of the dike is presented. This development aims at filling the gap between more classical 2D and purely 3D approaches, by optimising a compromise between acquisition cost and model reliability. Applied to real data sets this tool supplies a new understanding of the interpretation capability of the inversion results. 


\section{Near Surface \\ Geoscience 2012}

\section{Introduction}

In France, EDF (Électricité De France) is in charge of managing the large hydraulic structure stock dedicated to producing hydroelectricity. This responsability is associated with high economical and safety issues. Overtopping and internal erosion are the main mechanisms of dikes failure and represent more than $90 \%$ of the accidents (Foster et al., 2000; Fell \& Fry, 2007).

Among other geophysical methods, DC-electrical resistivity imaging (ERI) is being widely used on earth embankment dikes, either for extensive survey of large sections (a few $\mathrm{km}$ ) or for higher resolution surveys on shorter sections (a few 100m) previously identified as higher hydraulic risk zones (Fauchard and Mériaux, 2007). This method is also selected owing to its high sensitivity to internal erosion consequences (modifications of clay content, water content, temperature and porosity) (Johansson, 1997; Sjödahl et al., 2006).

However, using ERI in a conventional manner is likely to yield image artefacts (Sjödahl et al., 2006) when the processing is realized with $2.5 \mathrm{D}$ inversion software. This study aims to show that a bad management of the dike complexity during the inversion process is the origin of these artefacts. To overcome this limitation, a new inversion algorithm specially created to take into account the complex behaviour of the dike is presented. This development aims at filling the gap between more classical 2D and purely 3D approaches, by optimising a compromise between acquisition cost and model reliability.

In this paper, we first briefly present the consequences of the complex behaviour of the dike on a 2D longitudinal ERI campaign. Then, principle of the new inversion codes is presented. Then a special importance is given to the a priori information that can be inferred from the preliminary study and the way to manage this information during the inversion process. This methodology is applied to 2D ERI campaign acquired on a real hydraulic structure. Results show that the complex behaviour of the dike can be better take into account (presence of a water reservoir, topography of the dike) with this method and supply a relevant way to process 2D-ERI "high outputs" campaign.

\section{Pitfalls of a 2D-ERI longitudinal survey on a dike}

For cost effectiveness reasons, ERI is usually applied in a "classical" way: a set of equidistant electrodes is aligned along the longitudinal direction on the dike crest, slope, or toe. However, the geo-electrical behaviour of dikes is fully $3 \mathrm{D}$ due to the internal composition and the topography. Moreover, 2D-ERI measurement campaigns are mostly interpreted using 2.5D inversion softwares (e.g. Res2dinv) which can lead to 3D artefacts on the results.

In the framework of dike survey, it is important to differentiate 3D effects due to :

1. The presence of external media (e.g. the water reservoir, a concrete facing) or the topography of the dike.

2. The internal resistivity variation of the medium (e.g. the presence of a core, a foundation).

The reason why it is important to differentiate these two effects is that the purpose of imaging is the dike and not the water reservoir. In addition, the topography of the structure and the resistivity of the water reservoir are elements that can be measured directly without having to carry out destructive measurements.

Figure 1 presents the result of a numerical test which aims to quantify the effect of the topography of a dike and of the water reservoir on a measure. The effects of inter electrode spacing and the distance (d) between the quadrupole and the water reservoir are also studied. The result indicates that the effect of the water reservoir is higher when the distance between the quadrupole and the reservoir decreases and can scale up to $35 \%$ when inter-electrode spacing is $20 \mathrm{~m}$. Measurements quadrupole correspond to a "wenner alpha" protocol. To compute the apparent resistivity a conventional geometrical factor is 


\section{Near Surface \\ Geoscience 2012}

employed (2 $2 \pi \mathrm{a})$. Consequently, the strong effect of the topography and the water reservoir must be taken into account to avoid image artefacts and allow a robust result of inversion.

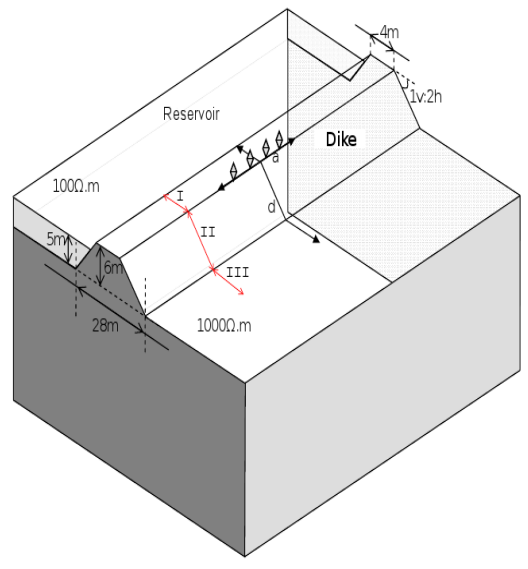

(a)

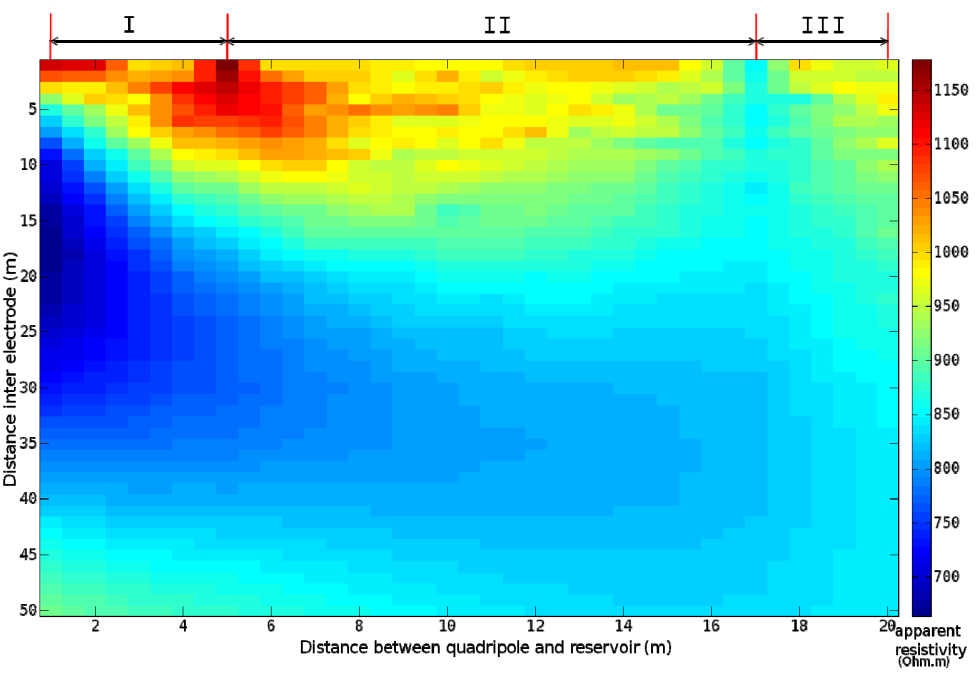

(b)

Figure 1 This figure presents (a) a scheme of the model used for the numerical test and (b) the result of the apparent resistivities simulated on the model at different distances of the reservoir and for various electrode separations. Three distinct regions are shown (I,II,III).

\section{A 2D+ inversion procedure}

The previous paragraph has presented some 3D effects intrinsic to a 2D-ERT procedure on a dike. It has also showed that these effects can be partly quantified. The objective of this paragraph is to present a cost effectiveness method taking most of the 3D effects into account.

The diffusion of an electrical field is a highly non-linear problem and a normalisation technique cannot completely take into account this nonlinearity (Marescot et al., 2006). Therefore, it is necessary to develop inversion methods capable of taking this non-linearity into account. To limit the financial cost of the acquisition and the computational cost of inversion, new inversion codes specifically adapted to the dikes problem are developed. These codes are named ' $2 \mathrm{D}^{+}$' and permit a $2 \mathrm{D}$ inversion that accounts for a part of the full 3D geo-electrical behaviour of a dike (The topography effect and water reservoir effects are taken into account).

To take into account this kind of information (e.g. topography, resistivity of the reservoir), a new methodology for meshing the direct problem and discretizing the inverse problem is used. The method, inspired by the triple grid method (Günther et al., 2006), consist to first create a discretization based on our a priori on the medium (Figure 2.a) and then to mesh this medium to solve the direct problem (Figure 2.b). However, this principle, although allowing an explicit integration of information on the environment, leads a higher inversion cost.

To solve the direct problem a finite element method is selected and meshes are deformed to simulate the topography. For the inversion, following the assumption that internal variations of the dike must be smooth, an OCCAM inversion type algorithm is implemented (Constable et al., 1992).

In conclusion, this new code provides a cost effectiveness manner to invert data obtain in high output conditions (2D-ERI longitudinal, figure 3.a) and permit a take into account of all external 3D effects (water reservoir, topography). A previous parametric study showed that a concrete facing does not have a significant effect on the measurement compared with the topography and the reservoir. 


\section{Near Surface \\ Geoscience 2012}

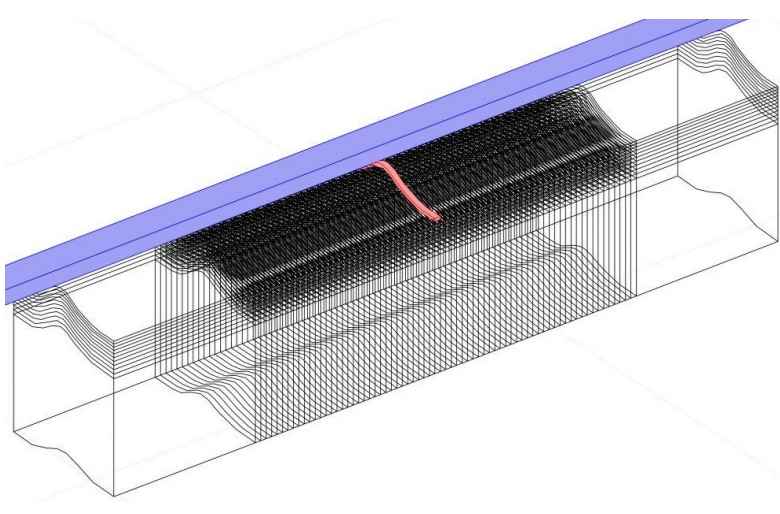

(a)

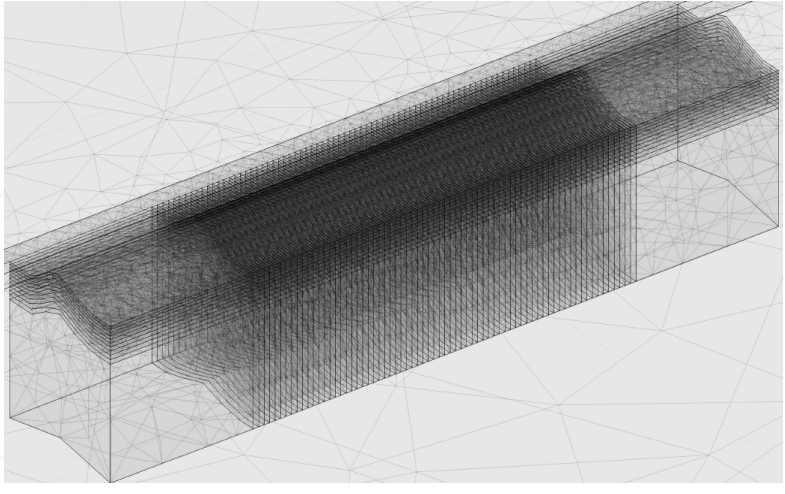

(b)

Figure 2 figure (a) presents the discretization of the inverse problem. The water reservoir (represented in blue) is simulated with just one inversion cell. The pink cell illustrates one of the deformed inversion cells composing the dike. The illustration (b) presents the finite element mesh used to resolve the direct problem.

\section{D-ERI longitudinal survey on a real hydraulic structure: results and discussion}

A survey in high output conditions is realized on real hydraulic structure of EDF (Figure 3.a). 96 electrodes were positioned every $5 \mathrm{~m}$ at the centre of the crest of the hydraulic structure. A WennerSchlumberger acquisition procedure was used to acquire data. Picture 3(a) shows the location of the electrode cable and the position of the water reservoir.

Figures 3(b) presents an inversion result obtained with the $2 \mathrm{D}^{+}$code. This result is presented at the third iteration with an RMS error of $0.62 \%$. The discretization of the inverse problem consists of approximately 3500 cells for the dike and one cell for the water reservoir following the principle presented figure 2 . The result highlights a resistive layer between 1 and $8 \mathrm{~m}$ depth (R1) and two conductive anomalies (A1 and A2) can be interpreted inside the R2 layer. In conclusion, usual artefacts due to the presence of the effect of the water reservoir (that appear with conventional 2.5D software) are inexistent suggesting the superiority of this result.

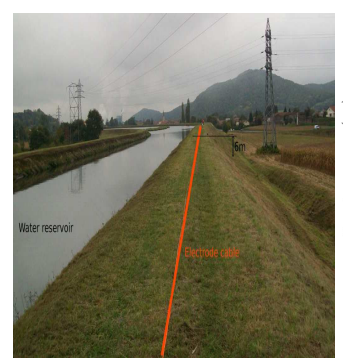

(a)

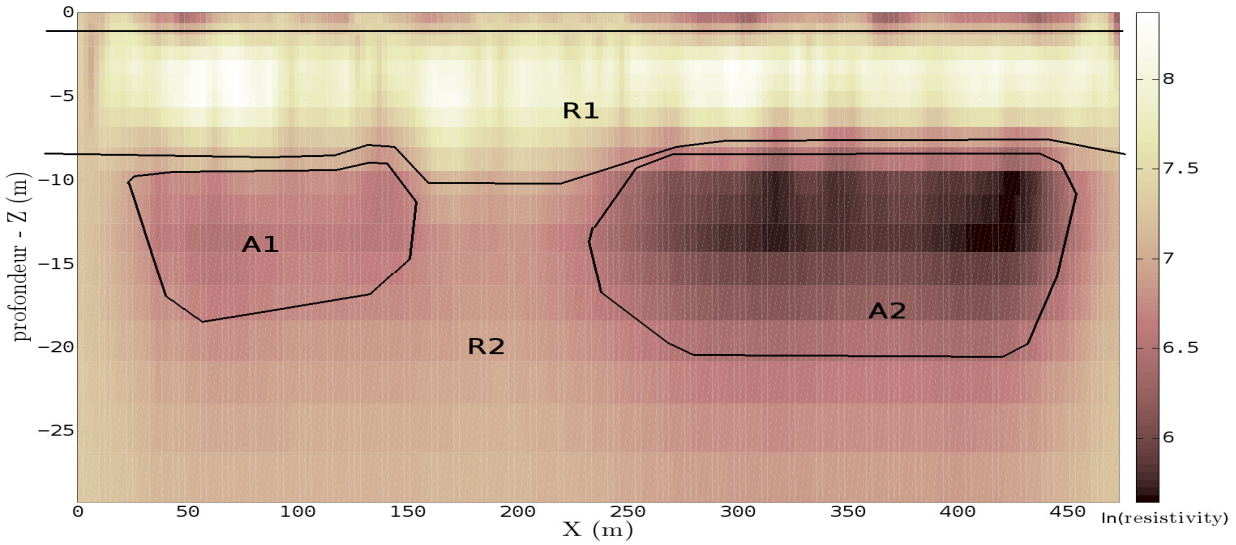

(b)

Figure 3 Figure presents (a) a picture showing the dike and the electrode cable location (in orange) and (b) the $2 D^{+}$inversion result from a Wenner-Schlumberger dataset obtained on medium (a). Two layers are differentiated (R1 and R2) and two anomalies must be identified (A1 and A2).

\section{Impact of the prior information on the inversion result}

The way the a priori information (shape and resistivity of the water reservoir) is incorporated into the inversion process can have a large impact on the inversion result. 


\section{Near Surface \\ Geoscience 2012}

During the study, we focused a part of our attention on how the a priori information must be implemented in function of the quantity of information and its quality.

Indeed, when the medium is not well known, the inversion must let more freedom (with a low damping factor) and/or with a high number of inversion cells. Conversely, in our case, several measurements have indicated that the resistivity of the reservoir was strongly homogeneous (because of a current in the reservoir). This knowledge has led us to not discretize the reservoir into several cells and impose strongly the resistivity of the reservoir with a high damping factor. Finally, a study concerning the robustness of the result (resolution matrix method) (Menke, 1984) indicates that imposing the resistivity of the reservoir increases the model resolution of the cell composing the dike and thus the robustness of the imaging result.

\section{Conclusions \& prospects}

2D-ERI is a widely used method for surveying and monitoring hydraulic structures. However, processed in a conventional manner, this method can lead to misinterpretation of the imaging result. To prevent these pitfalls, a new method, called $2 \mathrm{D}^{+}$, is presented. The objective of this method is to provide a treatment that can reflect the complexity of the structure without increasing the cost of measurement on the field.

This method is applied to real data acquired on a hydraulic earth structure. Results show that this method improves the robustness of the inversion process and thus the reliability of the interpretation. This procedure is now commonly applied to high-output 2D surveys, and we hope that it will be soon available for 3D high-resolution survey and monitoring of short stretches of dikes.

\section{Acknowledgements}

We would like to thanks EDF - CIH and more particularly Jean Robert Courivaud and Julien Cintract for the funding of part of the work and for the GPS assistance on-site.

\section{References}

Constable, S. C., Parker, R.L. and Constable, C.G. [1987] Occam's inversion - A practical algorithm for generating smooth models from electromagnetic sounding data. Geophysics, 52, 289-300.

Fauchard, C. and Mériaux, P. [2007] Geophysical and geotechnical methods for diagnosing flood protection dikes. Guide for implementation and interpretation. Editions Quae.

Fell, R. and Fry, J.-J. [2007] Internal erosion of dams and their foundations. Taylor \& Francis, London.

Foster, M., Fell, R. and Spannagle, M. [2000] The statistics of embankment dam failures and accidents. Canadian Geotechnical Journal, 37, 1000-1024.

Günther, T., Rücker, C. and Spitzer, K. [2006] Three-dimensional modelling and inversion of dcresistivity data incorporating topography - II. Inversion. Geophysical Journal International, 166, 506-517.

Johansson, S. [1997] Seepage monitoring in embankment dams. PhD thesis, Royal Institute of Technology, Stockholm.

Marescot L., Rigobert, S., Palma Lopes, S., Lagabrielle, R. and Chapellier, D. [2006] A general approach for DC apparent resistivity evaluation on arbitrarily shaped 3D structures. Journal of Applied Geophysics, 60, 55-67.

Menke, W. [1984] Geophysical data analysis: Discrete inverse theory. Academic Press Inc.

Sjödahl P., Torleif, D. and Zhou, B. [2006] 2.5D resistivity modeling of embankment dams to assess influence from geometry and material properties. Geophysics, 71, 107-114. 